\title{
Online Mapping Tools for Geolocating Amish Settlements
}

\author{
Andrew M. Wilson ${ }^{1}$ \\ Assistant Professor \\ Environmental Studies Department \\ Gettysburg College \\ Brian Lonabocker \\ Undergraduate Research Assistant \\ Environmental Studies Department \\ Gettysburg College
}

Megan Zagorski

Undergraduate Research Assistant

Environmental Studies Department

Gettysburg College

\begin{abstract}
This technical note demonstrates the value of using online mapping tools as a method of geolocating Amish settlements. Primarily using freely available Bing and Google maps and published lists of the addresses of Amish ministers, we geolocated 1,362 Amish households in Ohio and 1,203 in Pennsylvania, representing about 10\% of Amish households in those states. From these data we were able to derive a population density map of the Amish across Ohio and Pennsylvania. We caution that our map is merely a model and based on several assumptions, but the product is a finer resolution map of Amish distribution than has previously been published. We add that the locations of Amish schools provide another promising avenue for geolocation of Amish settlements, but we were not able to locate sufficiently comprehensive lists to include them in our analysis.
\end{abstract}

\section{Key Words}

Amish; Population density; Distribution; Settlement; Ohio; Pennsylvania

\section{Acknowledgements}

We thank Lizzy Cooper, Ryan Donnelly, Sam Donnelly, Micaela Edelson, Louis Gorst, Jared Jones, Ben Langey, Erin Palmer, Rachel Pruitt, and Crystal Williamson - undergraduate students in the Environmental Studies Major at Gettysburg College - for their diligent assistance collating data. Salma Monani (Associate Professor, Gettysburg College) provided much encouragement and advice. Joseph Donnermeyer (Professor, The Ohio State University) was gracious in supplying data and advice. We also thank Jeff Bach, Donald Kraybill, and Edsel Burge (Young Center for Anabaptists and Pietist Studies, Elizabethtown College) for allowing access to the Young Center Research Collections. Brian Lonabocker and Megan Zagorski were funded by the Gettysburg College Provost's Office and a grant from the Howard Hughes Medical Institute. 


\section{Introduction}

Interest in the geographical distribution of Anabaptist settlements has a long history (Anderson and Donnermeyer 2013). Scholars who study demographic changes in Anabaptist communities are often interested in the size and location of each settlement and the changes in those settlements over time. Past studies have often focused on locations and population estimates of each settlement, often at county or even state scales (e.g. Luthy 2009; Donnermeyer and Luthy 2013), which are sufficient for many fields of academic interest. However, these community scale inventories are not of sufficient spatial resolution for some analyses.

Our interest in Amish settlements stems from a long-standing belief that Amish farming inherently incorporates facets of agriculture that can be described as "sustainable" (e.g. Stinner, Paoletti, and Stinner 1989; Kraybill, Johnson-Weiner, and Nolt 2013). The aspect of sustainable agriculture that we are interested in is the maintenance of wildlife populations (Harwood 1990). Our intention was to utilize extensive bird survey data gathered for statewide bird atlas projects in Pennsylvania (Wilson, Brauning and Mulvihill 2012) and Ohio (Rodewald, et al. [in press]) to assess whether landscapes with high densities of Amish settlement had different bird populations to nearby agricultural landscapes with no Amish settlements. Despite our landscape-scale analytical approach, our dependent data - bird counts - are gathered at individual locations using a point count bird survey methods (Bibby, et al. 2000). Hence, to relate the density of Amish farms to these data, we need a finer spatial resolution than at the county or settlement scale. The results of the ecological analysis will be published elsewhere. However, we believe that our method for geolocating Amish settlements is of wider application and interest and hence document our methods here.

In this technical report, we demonstrate our approach to producing a fine-scale map of the density of Amish settlements in Ohio and Pennsylvania. We used published addresses of Amish ministers to develop a proxy for the distribution of the Amish populations across both states. These two states have the largest and longest established Amish settlements in the world, between them accounting for almost half of the Amish population of the United States (Donnermeyer, Anderson, and Cooksey 2013).

\section{Methods}

Our primary data source was the New American Almanac 2010 and 2012 (Raber 2009 and 2011). Known colloquially as "Raber's Almanac," this annual publication lists nearly all addresses of ministers and bishops in each Amish church district. Typically, Raber's Almanac lists three living church leaders and the most recently deceased minister. We aimed to geolocate the addresses of all ministers who were alive during our study period (2004 to 2009 in Pennsylvania, 2006 to 2011 in Ohio), years that correspond to the fieldwork for the bird atlas projects. 
The addresses from Raber's Almanac were typed into either Bing (C) 2015 Microsoft) or Google (C2015 Google) maps. Often the address entered did not fall directly on top of a residence, so we searched the aerial imagery for the nearest residence that showed characteristics associated with the Amish:

- Rural residence, typically a farmhouse with out-buildings

- Often evidence of more than one residence in a cluster (extended families and retired Amish often reside in separate houses on the same property, per Kraybill, JohnsonWeiner and Nolt 2013)

- Buggy or buggy tracks

- No evidence of automobiles, tractors, or other gas-powered vehicles

- Often a vegetable garden and no elaborate landscaping around the property

- Circular or semi-circular driveways

- Clothes on a clothes line

While presence or absence of these characteristics does not allow for definitive identification of Amish residences, combinations of these are strong indicators of such. It should be noted that the houses located may not be the precise house inhabited by a minister, but because we used the distribution of ministers as a proxy measure for the distribution of the whole Amish community, we do not believe that such discrepancies are sufficient to affect the results of our study. In the majority of cases, the address as input into Bing or Google maps resolved the location of the residence with little ambiguity, but there were many where the resulting location was uncertain. In those cases, we typically used both of the mapping services to aid resolution, and in some instances used additional online tools, such as real estate listings, to assist with locating the Amish residence. Finally, Google "Street View" (C2015 Google) was a useful additional tool; the street view often provided additional anecdotal evidence that a residence was occupied by an Amish household (such as clearly recognizable plain people in the images!).

Once the likely location of the Amish residence was found, its geographical coordinates were obtained by right-clicking the online map (WGS 1984, decimal degrees). The names of each Amish minister, the settlement, the address, and the XY coordinates were stored in a spreadsheet, which was then imported into ArcGIS 10 (ESRI 2011) for analysis. To produce a map of the estimated density of the Amish populations in Ohio and Pennsylvania, we created a one kilometer square across both states using the "Create Fishnet" tool in ArcGIS. We then attached counts of residences to the centroid of each one kilometer square using a spatial join, and then multiplied the count by a factor to convert from the count of ministers to estimated number of Amish. This factor was derived by dividing the estimated Amish populations of each 


\section{Figure 1: Location of Amish Ministers in Pennsylvania in 2004 to 2009 and Ohio in 2006 to 2011}
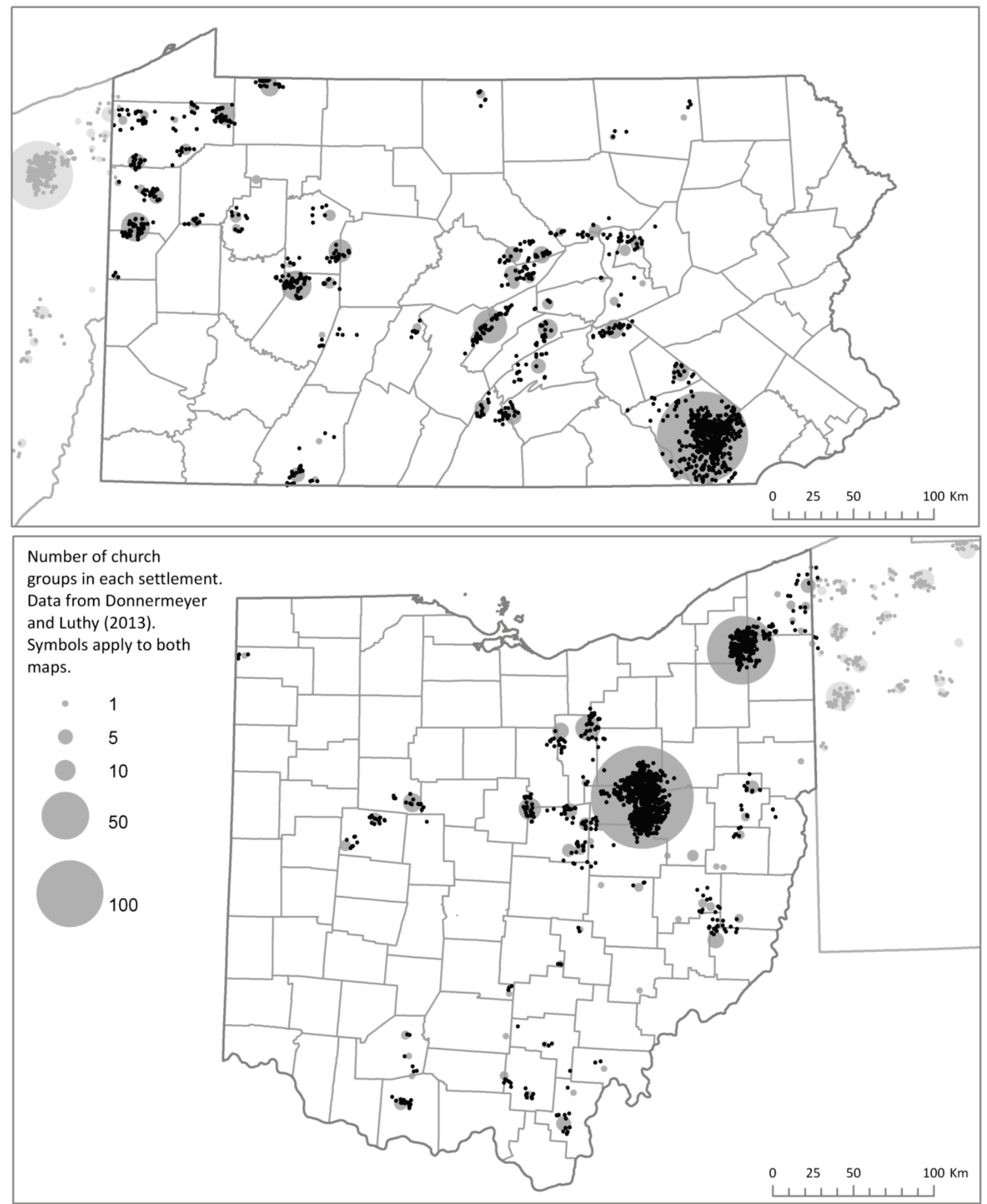

Black dots: Amish ministers - Grey circles: Amish settlements 
state in 2010 (from Donnermeyer, Anderson, and Cooksey 2013) by the number of geolocated Amish ministers' residences. The estimated density of Amish residents was then interpolated to produce a smoothed density map using "normal kriging" in ArcGIS.

\section{Results}

We geolocated 1,362 suspected Amish houses in Ohio and 1,203 in Pennsylvania. Assuming a mean household size of five people (Greska 2002), and populations of 60,308 and 59,025 respectively in 2010 (Donnermeyer, Anderson, and Cooksey 2013), we estimate that we geolocated more than 11\% of Amish households in Ohio and more than 10\% of Amish households in Pennsylvania.

The distribution of geolocated households closely follows the established distribution of Amish settlements (e.g. Donnermeyer and Luthy 2013), but the mapping by household provides finer resolution of both density and settlement shape (Figure 1). The distribution of geolocated households varies among settlements, with some being very dense and clustered while others are more scattered. The pattern of households is strongly influenced by land use, which is itself a function of topography in many areas of Pennsylvania and Ohio. This is particularly marked in the Ridge and Valley province of central Pennsylvania (Sevon 2000), where Amish households are distributed linearly along the heavily farmed valley bottoms (Figure 2; agricultural areas defined using 2006 National Land Cover Data, http://www.mrlc.gov/nlcd06_data.php).

Estimated population densities exceeded 40 Amish persons per square kilometer over extensive tracts within the central areas of the three largest Amish settlements: Greater Holmes County, Ohio; Lancaster County, Pennsylvania; and Geauga / Trumbull Counties, Ohio (Figure 3). Locally within those areas, densities may be higher than 200 persons per square kilometer, according to our raw data.

\section{Discussion}

Our maps based on geolocated Amish ministers' residences provide, we believe, the finest spatial resolution of any published maps of Amish populations across state scales. While our map of Amish population density may have limited applications, it provides sufficient spatial resolution to assist with landscape scale analysis, such as our study of the associations of farmland birds with Amish farming.

Although our map provides great utility for spatial analyses involving Amish populations, we must be clear that in the absence of comprehensive census data, it is merely a model of the population distribution, and as such is subject to assumptions and sources of error. Primary among these is the possibility that some of the geolocated households were misidentified, i.e., they are not occupied by Amish. The most likely cause of misidentification is where a household is in fact occupied by other plain people, especially conservative Mennonites whose settlements are intermingled with Amish settlements in many areas (Anderson and Donnermeyer 2013). 


\section{Figure 2: Distribution of Amish Ministers (2004 to 2009) in the Ridge and Valley Province of Central Pennsylvania}
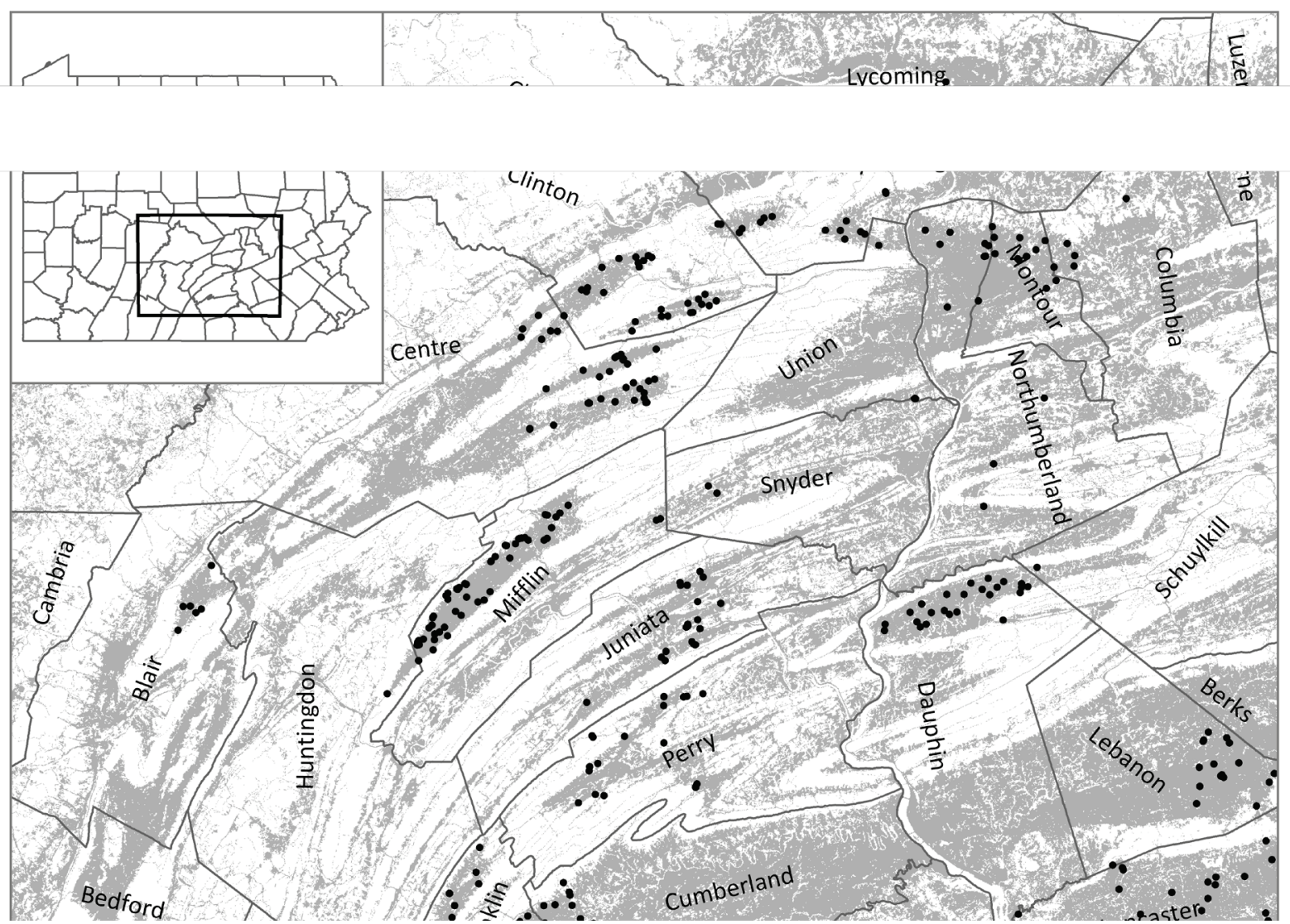

Gray shading is agriculture and grassland circa 2005 (NLCD)

Conversely, while our primary data sources (Raber 2009, 2011) provide very comprehensive lists of Amish ministers, they are not complete (Donnermeyer and Luthy 2013), which will result in an under-documentation of Amish in some areas. Also, a small number of residences listed in Raber's almanacs could not be geolocated using our methods (around 20 in each state). Despite the potential for under-recording, we estimate that we likely geolocated more than $10 \%$ of all Amish households across both states.

Mismatches between the dates of our study and the aerial imagery might also have contributed to some uncertainty. The Bing maps used for our study region are dated 2011/2012 (determined using http://mvexel.dev.openstreetmap.org/bing/), while the Google imagery was dated 2012 to 2014. Such uncertainty is likely more acute in settlements with considerable inward or outward migration of Amish families, which may cause ownership of residences to be transferred to and from the Amish.

Our estimates of population density are derived by applying correction factors of 44.27 for Ohio and 49.06 for Pennsylvania — based on the ratio of geolocated address to the 2010 


\section{Figure 3: Estimated Density of the Amish in Ohio and Pennsylvania (2010)}

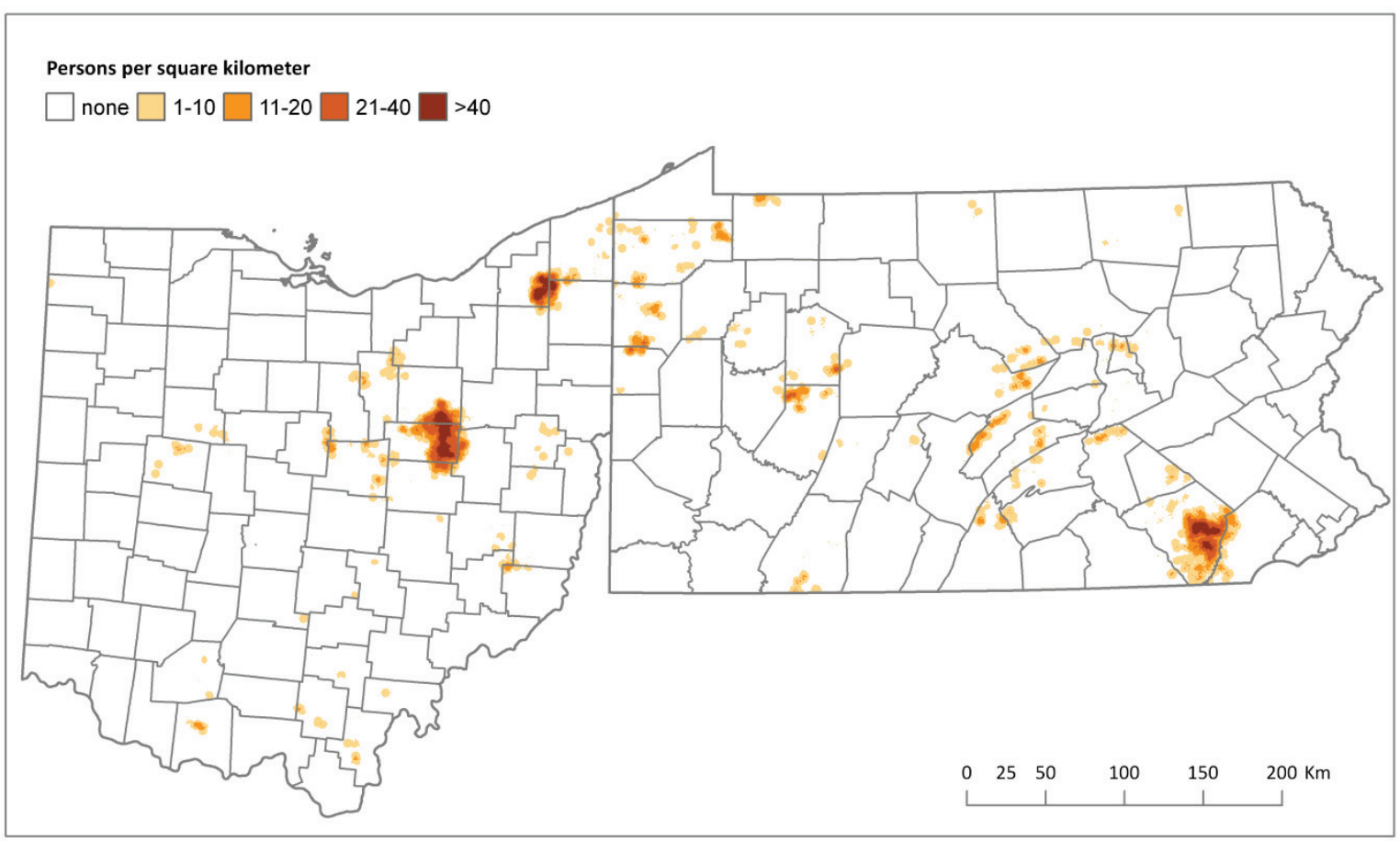

population. However, it is known that household size and number of households per church district vary, especially in relation to the age of the settlement (Donnermeyer, Anderson, and Cooksey 2013). This likely resulted in an underestimate of densities in long established settlements, which typically have more households per district.

We would like to bring attention to another data source that future researchers could utilize to geolocate Amish settlements: Amish schools. Amish schools are listed on several searchable online databases (e.g. http://www.privateschoolreview.com/) and are readily identified from aerial imagery, showing characteristic one-room schools, often with two outbuildings (lavatories) and a well-worn softball diamond (e.g. Figure 4). It was our intention to use these in conjunction with Amish ministers' residences in our study, but while we geolocated some 198 Amish schools in Pennsylvania (Figure 5), we failed to find schools in some settlements, especially in the northwest of Pennsylvania, where many Amish settlements are relatively recent (Donnermeyer and Luthy 2013).

Finally, while the addresses of Amish ministers are in the public domain via Raber's almanac, we acknowledge that detailed spatial data of their locations in the form of a geospatial database is not. We encourage other researches to consider the ethical dimensions of using modern technology to locate the addresses of a population who shun technology, and caution against widespread dissemination of electronically collated lists of addresses. 
Figure 4: Aerial Imagery of a Typical Amish School, Lancaster County, PA

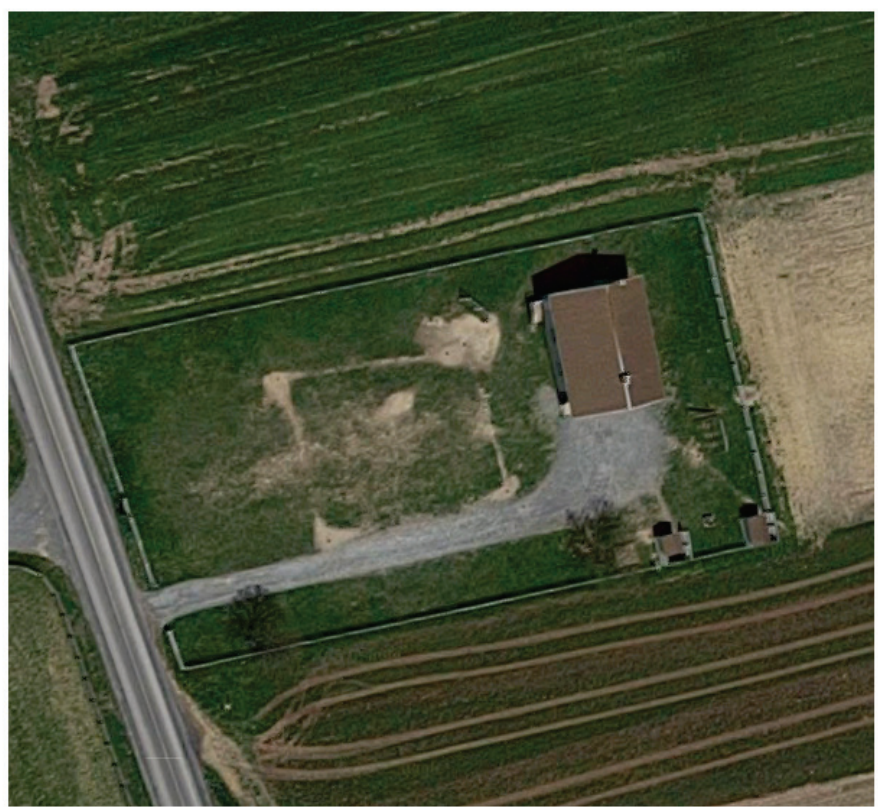

Image Copyright (C) DigitalGlobe

Figure 5: Distribution of Amish Schools in Pennsylvania, Geolocated from Online Sources

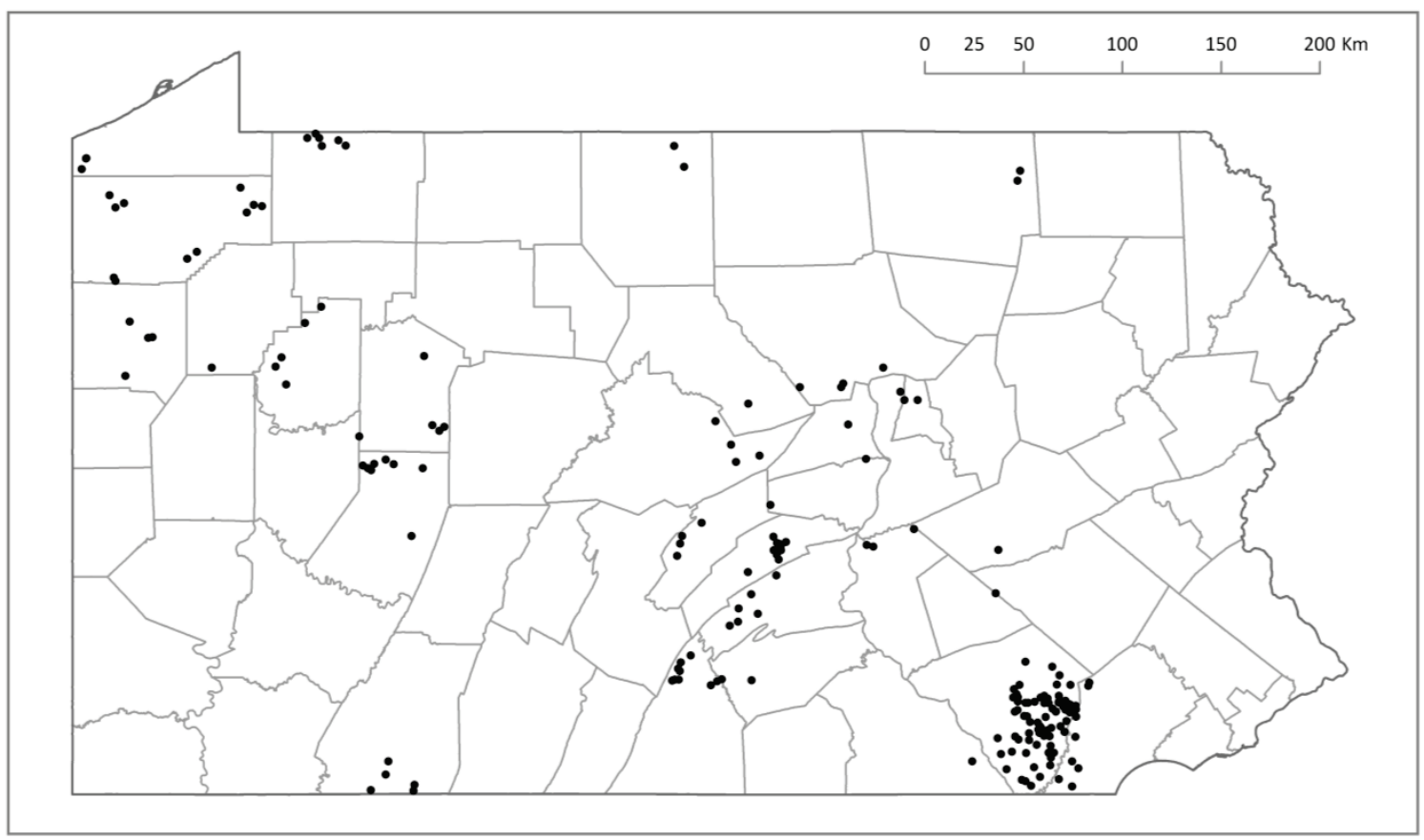




\section{Endnote}

${ }^{1}$ Contact information: Andrew Wilson, Environmental Studies Department, Gettysburg College, 300 North Washington St., Gettysburg, PA 17325; awilson@gettysburg.edu

\section{References}

Anderson, Cory, and Joseph Donnermeyer. 2013. "Where Are the Plain Anabaptists?" Journal of Amish and Plain Anabaptist Studies 1(1):1-25.

Bibby, Colin, Neil Burgess, David Hill, and Simon Mustoe. 2000. Bird Census Techniques $2^{\text {nd }}$ ed.]. London, England: Academic Press.

Donnermeyer, Joseph, Cory Anderson, and Elizabeth Cooksey. 2013. "The Amish Population: County Estimates and Settlement Patterns." Journal of Amish and Plain Anabaptist Studies 1(1):72-109.

Donnermeyer, Joseph, and David Luthy. 2013. "Amish Settlements across America: 2013." Journal of Amish and Plain Anabaptist Studies 1(2):107-29.

ESRI. 2011. ArcGIS Desktop: Release 10. Redlands, CA: Environmental Systems Research Institute.

Greksa, Lawrence. 2002. "Population Growth and Fertility Patterns in an Old Order Amish Settlement." Annals of Human Biology 29(2):192-201.

Kraybill, Donald, Karen Johnson-Weiner, and Steven Nolt. 2013. The Amish. Baltimore, MD: Johns Hopkins University Press.

Harwood, Richard. 1990. "A History of Sustainable Agriculture.” Pp. 3-19 in Sustainable Agricultural Systems, edited by Clive Edwards, Rattan Lal, Patrick Madden, Robert H. Miller, and Gar House. Ankeny, IA: Soil and Water Conservation Society.

Luthy, David. 2009. Amish Settlements across America: 2008. Aylmer, ON: Pathway Publishers.

Raber, Aden. 2009. The New American Almanac, 2010. Baltic, OH: Raber's Book Store.

Raber, Aden. 2011. The New American Almanac, 2012. Baltic, OH: Raber's Book Store.

Rodewald, Paul, Matthew Shumar, Aaron Boone, David Slager, and Jim McCormac. [In Press]. Second Atlas of Breeding Birds in Ohio. University Park, PA: Pennsylvania State University Press. 
Sevon, Sevon. 2000. "Physiographic Provinces of Pennsylvania." Accessed December 10, 2015 (http://www.dcnr.state.pa.us/cs/groups/public/documents/document/ denr_016202.pdf).

Stinner, Deborah, Maurizio Paoletti, and Ben Stinner. 1989. "In Search of Traditional Farm Wisdom for a More Sustainable Agriculture: A Study of Amish Farming and Society." Agriculture, Ecosystems and Environment 27:77-90.

Wilson, Andrew, Daniel Brauning, and Robert Mulvihill. 2012. Second Atlas of Breeding Birds in Pennsylvania. University Park, PA: Pennsylvania State University Press. 